Published in final edited form as:

Expert Opin Ther Targets. 2013 March ; 17(3): 281-291. doi:10.1517/14728222.2013.740461.

\title{
Cathepsin B as a Cancer Target
}

\author{
Christopher S. Gondi ${ }^{1}$ and Jasti S. Rao ${ }^{1,2}$ \\ ${ }^{1}$ Department of Cancer Biology and Pharmacology, University of Illinois College of Medicine at \\ Peoria, Peoria, IL, USA \\ ${ }^{2}$ Department of Neurosurgery, University of Illinois College of Medicine at Peoria, Peoria, IL, USA
}

\section{Abstract}

Cathepsin B is of significant importance to cancer therapy as it is involved in various pathologies and oncogenic processes in humans. Numerous studies have shown that cathepsin B overexpression is correlated with invasive and metastatic phenotypes in cancers. Studies have shown that abnormal regulation of cathepsin $\mathrm{B}$ causes cells to acquire an oncogenic character. Cathepsin B is normally associated with the lysosomes involved in autophagy and immune response, but its aberrant expression has been shown to lead to cancers. The proteolytic nature of cathepsin B has been attributed to the infiltrative nature of tumor cells, and it has been shown that cathepsin B is secreted into the extracellular matrix (ECM), thereby facilitating its destruction. Studies have demonstrated that suppression of the proteolytic activity of cathepsin B retards the infiltrative behavior of tumor cells. Further suppression of the expression of cathepsin B via antisense or RNAi also resulted in suppression of tumor growth. In addition, studies have shown that combined suppression of various molecules, such as proteases and protease receptors, including cathepsin B, can significantly suppress tumor growth. Therefore, targeting the activity or expression of cathepsin B is of significant therapeutic importance for cancer treatment.

\section{Keywords}

Cathepsin B; cancer therapy; cancer target; ECM; Cathepsin B signaling

\section{Introduction}

Cathepsins are lysosomal proteases that belong to the papain family. The name "cathepsin" is derived from ancient Greek "kata" meaning down and "hepsein" meaning to boil. More than a dozen cathepsins have been identified in various organisms (e.g., cathepsin A [1], cathepsin B [2], cathepsin C [3], cathepsin D [4], cathepsin E [5], cathepsin F [6], cathepsin G [7], cathepsin H [8], cathepsin J [9], cathepsin K [9], cathepsin L [10], cathepsin O [11], cathepsin S [12], cathepsin T [13], cathepsin V [14], cathepsin W [15], cathepsin Y [16], and cathepsin $Z$ [17]). Of all the cathepsins, studies have shown that cathepsin B is of significant importance as it is involved in various pathologies and oncogenic processes. In normal physiological conditions, cathepsin B is tightly regulated in a well-coordinated manner at multiple levels. However, during malignant transformation, the regulation of cathepsin B can be altered at multiple levels and thereby resulting in the overproduction of cathepsin B. Overexpression of cathepsin B has been observed in various malignancies, including brain [18], lung [19], prostate [20, 21], breast [22], and colorectal cancer [23]. The altered regulation of cathepsin B can occur at various levels [24, 25]. Cathepsin B has been mapped to chromosome 8p22 [26-28], and interestingly, the importance of this region as a tumor suppressor has also been identified in many studies [29-31]. One of the prominent features of oncogenic cathepsin B is its alternate splicing [32]. The cathepsin B gene, also known as the $C T S B$ gene, consists of 13 exons, which include exons $2 \mathrm{a}$ and $\mathrm{b}$. The portion that codes for cathepsin B is approximately $1 \mathrm{~kb}$ in size with the overall gene spanning at 
least $27 \mathrm{~kb}$ [26]. A detailed description of the alternate splicing of cathepsin B is discussed by Baici, et al. [32]. In addition, cathepsin B has been postulated to have many nononcogenic roles, including being anti-amyloidogenic and a neuroprotective protease. Cathepsin B was found to be associated with amyloid plaques in Alzheimer's disease brains and has been suspected to increase A-beta production. Mueller-Steiner, et al. [33] have demonstrated that cathepsin B actually reduces levels of A-beta peptides, especially the aggregation-prone species A-beta1-42 through proteolytic cleavage. Researchers have also demonstrated that cathepsin B may be involved in reducing mutant huntingtin protein levels through macro-autophagy and that it functions as a neuro-protector [34]. It is known that cathepsin B is an important molecule involved in autophagy [35], and under normal conditions, plays an important role in the maintenance of physiological function and also as a scavenger [36]. Cathepsin B has been shown to be involved in invasion and migration [37, 38]. It appears that the abnormal regulation of cathepsin $B$ causes cells to acquire an oncogenic character.

\section{Oncogenic role of cathepsin B}

Numerous studies have shown that cathepsin B overexpression is correlated with invasive and metastatic cancers [39-41]. Cathepsin B is known to interact with cystatins [42, 43] and annexin II tetramer (p11), which is also known as S100A10 [44]. These interactions place cathepsin B at crucial positions for the proteolytic activation of ECM components, thereby enabling ECM degradation. It has been observed that the promoter of cathepsin B contains a GC-rich region including many SP1 sites, similar to a housekeeping gene [45]. These SP1 sites are known to increase in tumor cells [46]. Interestingly, it has been observed that cathepsin B is also involved in autophagy and cannibalism, as researchers have shown that tumor cannibalism is advantageous in tumor malignancy and is possibly involved in specific immune resistance [47], enabling tumor cells to recycle nutrients and maintain a proliferative and infiltrative phenotype. This could also explain why the cores of highly infiltrative tumors are necrotic. Various studies have shown that cathepsin B has an active role in initiating the proteolytic cascade involving uPA, plasminogen and plasmin, and it has also been shown to activate latent TGF- $\beta$ [48]. Cathepsin B appears to support a promalignant phenotype by enabling the maintenance of active proteases by actively suppressing their inhibitors. For example, cathepsin B enhances the activity of the matrix metalloproteinases (MMPs) by destroying their inhibitors (e.g., TIMP1 and TIMP2) in human articular chondrocytes and maintains a high level of MMPs, thereby promoting ECM degradation and angiogenesis [49]. Overall, cathepsin B appears to have both pro- and antioncogenic roles.

\section{Regulation of cathepsin B}

Most malignant tumors show increased transcriptional activation of cathepsin B. More than a decade ago, Qian, et al. identified that increased expression of cathepsin B in B16a melanoma cells is due to a specific increase in the amount or activity of a transcriptional activator of the cathepsin B gene [50]. Later, the research group of Sloane, et al., found that more than one promoter could direct expression of human cathepsin B as shown by multiple transcript species that were detected in their studies. This could result in the production of alternative splicing in the $5^{\prime}$ - or $3^{\prime}$-untranslated regions, and possibly the use of alternative promoter regions, and also indicate that membrane association and secretion of cathepsin B is not a random process in the tumor cell, but is part of a tightly controlled system [24, 51]. Further, it was also reported that differentiating agents, such as inducers of monocytic differentiation agent PMA, calcitriol (D3), and sodium butyrate $(\mathrm{NaB})$, and inducers of granulocytic differentiation [all-trans retinoic acid (RA) and 9-cis retinoic acid (9-cis RA)] increase cathepsin B mRNA levels in a dose-dependent manner [52]. As newer molecular 
techniques developed, it was further determined that the regulation of cathepsin B transcription is by Sp1 and Sp1-related factors, which is mediated through multiple GC boxes on its promoter [53]. Other researchers have also come to the same conclusion that variation of cathepsin B expression is largely due to different levels of Sp1 presence [54]. Moreover, it has also been shown that myogenic transcription factor mediates the activation of cathepsin B expression during myogenic differentiation [55] and that an E-box at nucleotides -7 to -2 of the cathepsin B promoter is critical to the expression of cathepsin B.

Additionally, the binding of USF-1 and USF-2 to this E-box can regulate cathepsin B promoter activity [56], thus highlighting its role in differentiation. Interestingly, it was further shown that USF2c, an isoform of USF2, regulates the expression of cathepsin B by binding to the E-box element in the cathepsin B promoter functioning as a repressor [57]. Further, it was also recently shown that the EMT activator ZEB1 (zinc finger E-box binding homeobox 1) is a crucial promoter of metastasis and stemness, which functions by suppressing stemness and mediates inhibition of microRNAs involved in tumor regulation [58]. These findings make it clear that cathepsin B may also be involved in EMT and may also be regulated by various EMT and stemness-related factors. All of these findings highlight the fact that cathepsin B is a multifaceted molecule and is regulated at multiple levels with diverse function, some of which are still not clear.

\section{Cathepsin B cascade}

The aberrant expression of cathepsin B, which is normally an intracellular lysosomal protease, has been observed in the ECM of malignant tumors. Cathepsin B is secreted as a pro-enzyme [59] and is activated to its active form via various molecules. The mechanism of secretion of cathepsin B to the pericellular surface of cancer cells is still unclear. It has been observed that human lung macrophages express four of the known cathepsins - cathepsins $\mathrm{B}, \mathrm{H}, \mathrm{L}$, and $\mathrm{S}$ [60]. It is also known that brain macrophages of microglial origin possess high levels of cathepsin B and L, and thus, these cells are potentially cytotoxic. These studies indicate that these cells can play a universal role in the defense of the lung tissue [60] and the neural parenchyma [61]. It is also known that cathepsin B is involved in bone resorption [62]. All of these data indicate that cathepsin B is an important part of the immune defense system and plays a vital role in healing.

Interestingly, cathepsin B has previously been identified as a lysosomal thiol proteinase that may have additional extralysosomal functions [63]. In cancer cells, activation of the cathepsin B gene is mediated by extracellular signals, which are probably mediated via the integrin-uPAR-uPA and the CD44-MMP complex supermolecular complex. This activation results in the overproduction of cathepsin B mRNA, which in turn, is processed to procathepsin B. This pro-cathepsin B is transported to the cell surface where it localizes on the annexin-p11 complex. Activation of pro-cathepsin B is via numerous mechanisms such as CathD, tPA and uPA, and we suspect that alternate splice variants can also auto-activate it. Cathepsin B is also known to activate pro-MMPs, which in turn, targets the ECM, causes ECM degradation and facilitates metastasis (Fig. 1). Interaction of MMPs, specifically MMP-2 and MMP-9, with CD44 on the cell surface occurs via the hemopexin domain [64]. It is speculated that these MMPs are activated or shed into the ECM via the action of cathepsin B and uPA. In other words, cathepsin B plays an important role in orchestrating the protease cascade and directing it towards the invasive fronts of metastatic cells. The activation of various proteases is usually mediated by plasmin, a broad spectrum protease. Other than plasmin, the only other known efficient activator of MMPs is cathepsin B [65]. Further, cathepsin B was also observed to activate trypsinogen-1 in pancreatitis [66], and pancreatic inflammation appears to increase the risk of pancreatic cancer [67]. Researchers have also found that infections from viruses such as Influenza-A virus elevates active 
cathepsin B in primary murine dendritic cells [68], contributing to the hypothesis that prolonged infections can lead to carcinogenesis [69]. Further, it was also recently observed that TLR3 signaling and cleavage are largely dependent on cathepsin B [70]. It has been shown that TLR3 detects double-stranded RNA produced during the replication cycle of most viruses and leads to the activation of the transcription factors NF- $\mathrm{\kappa B}$ and interferon regulatory factor (IRF) 3 , thus further leading to the production of type I interferons (IFNs) and pro-inflammatory cytokines, such as IL-6 and IL-8 [71]. Further, activation of the TLR3 pathway is also known to induce apoptosis in tumor cells via the activation of caspases 8 and 9 [72]. As such, cathepsin B may inactivate this TLR3-mediated apoptotic pathway, leading to the survival of tumor cells. It is also known that the pro-apoptotic activity of TLR3/TRIF/caspase 8 in melanoma cells is under the control of inhibitors of apoptosis (IAPs) [73]. It is also known that TLR3 signaling triggers apoptosis and induces growth arrest of LNCaP cells partially via the inactivation of the PI3K/Akt pathway and that treatment-associated autophagy plays a cyto-protective role, thereby leading one to speculate on the pro-oncogenic role of cathepsin B [74]. Interestingly, several systems have shown the involvement of cathepsin B in apoptosis regulation. The release of cathepsin B from the lysosomes may activate apoptotic pathways [75]. This dual nature of cathepsin B is interesting as studies show that cathepsin B serves as a pro-oncogenic molecule involved in ECM degradation, angiogenesis and metastatic induction; as an anti-apoptotic molecule suppressing the TLR3 pathway and maintaining a pro-survival state; and as a pro-apoptotic molecule involved in autophagy and immune response. The catalytic function of cathepsin B is dependent on the $\mathrm{pH}$. It is known that lysosomes have a low $\mathrm{pH}$ and provide the ideal environment for cathepsin B activation [76]. A similar type of environment is observed around the invasive front of tumor cells, as such tumors are considered to be more acidic than normal cells [77]. This leads one to speculate that the tumor microenvironment shows high cathepsin B activity. All of these aspects, such as the tumor microenvironment, secretion of cathepsin B and the activation of various proteases contribute to a malignant phenotype. This raises another question as to the mechanism of tumor cell survival under low $\mathrm{pH}$ conditions. It is known that cancer cells can survive under low nutrient conditions when compared to normal cells [78], but the mechanism of tolerance to low $\mathrm{pH}$ is still not clear. Cathepsin B is known to be localized in the lysosomes and to facilitate autophagy and immune responses by trafficking TNF-alpha-containing vesicles to the plasma membrane in macrophages $[60,79]$. Cathepsin $B$ is also known to be localized in the mitochondria [80] where it is thought to initiate cell death [81]. Interestingly, cathepsin B is also known to be localized to the nucleus where it is found to be associated with the nuclear scaffold [82] and is thought to be involved in cell division. A recent report suggests that cytoplasmic cathepsin B might be able to enter the cell nucleus and that cell death associated with cathepsin B is not triggered by its regular enzymatic activity but rather by an unknown mechanism of truncated cathepsin B [83]. A recent study was done to determine the trafficking of cathepsin B in thyroid carcinoma cells [84]. This study employed the use of GFP-tagged cathepsin B and showed that sub-cellular localization of proteolysis is a crucial step in regulation of tissue homeostasis. This study also concluded that any interference with protease trafficking resulting in altered regulation of the proteolytic events could lead to the onset and progression of cancer. These findings indicate that the normal regulation and distribution of cathepsin B is vital for cellular functioning and any aberrant expression of cathepsin B resulting from altered splicing or change in expression levels can significantly alter the homeostasis of cells and result in a malignant phenotype. These studies suggest that besides the $\mathrm{N}$-terminal signal peptide, other cathepsin B domains may contain patterns that are responsible for differentiated targeting to the mitochondria, the nucleus, or vesicles. These diverse functions of cathepsin B and its multifaceted role illustrate that cathepsin B as a molecule is still shrouded in mystery and many of its functions still remain unknown, but its role in the progression of cancer remains undisputed. Identification of cathepsin B as a 
prominent contributor to the malignant behavior of tumor cells has helped identify it as a possible target for cancer therapy.

\section{Therapeutic potential of targeting cathepsin B}

Numerous studies have shown that infiltrative tumors express high levels of proteases including cathepsin B [85-87]. Various therapeutic strategies have been developed to suppress proteolytic activity of proteases in an attempt to curb metastatic infiltration mediated by proteases. Among the strategies developed, chemical inhibitors, antibodies, and gene therapy approaches have shown promising developments. Inhibitors of cathepsin B have been isolated from various sources such as the marine bacteria Pseudomonas, marine sponges and other organisms [88]. Researchers have also observed that non-peptidic compounds, such as flavonoids, also showed strong cathepsin B inhibition properties. However, even with numerous compounds being isolated and identified, none have really shown any significant therapeutic potential. Recently, Shree, et al. [89] have demonstrated that cathepsin B expression in breast tumors plays a tumor protective role, and they showed that a combination approach to cathepsin B inhibition, which involved use of the compound JPM and the chemotherapy agent Taxol, significantly retarded tumor development. Researchers have also tried development of various hybrid inhibitors to suppress cathepsin $\mathrm{B}$ activity. For example, a bifunctional inhibitor has been developed that binds to cathepsin $\mathrm{B}$ and uPAR [90]; it behaves as a tight binding inhibitor of cathepsin B as well as an effective uPA receptor antagonist. Recently, a potato cysteine proteinase inhibitor (PCPI 8.7) was demonstrated to inhibit invasion in murine B16 melanoma cell by $21 \%$ [91]. Further, it has been demonstrated in leukemia cells that Imatinib-mediated apoptotic induction of CML cells is through LMP and cathepsin B-specific degradation of BCR-ABL, which shows that cathepsin B may also play a role as a cancer suppressor under appropriate conditions [92]. Parker, et al. have demonstrated that expression of Stefin A (also known as cystatin A) reduces distant metastasis in breast cancer, and they proposed that this may be due to the inhibition of cathepsin B [93]. Cystatin A is a well known inhibitor of cathepsin B [94], and its possible use as an inhibitor of cathepsin B is not new. Li, et al. [95] have demonstrated that overexpression of cystatin A has possible therapeutic implications in human esophageal squamous cell carcinoma cells. The evolution of cathepsin B inhibition from chemical inhibitors to biological inhibitors has now progressed to the use of gene therapy. As has been demonstrated by numerous researchers, cathepsin B is overexpressed in various cancers [87] and seems to play an important part in maintenance of the cancer phenotype. Targeting the expression of cathepsin B could have significant therapeutic implications. We have previously shown that cathepsin B expression is greatest in highly malignant astrocytomas, especially in glioblastomas, and is correlated with the malignant progression of astrocytomas [96]. Using this as a starting point, we attempted to downregulate cathepsin B using the anti-sense approach [97]. We observed that intracerebrally implanted SNB19 stable cathepsin B antisense cells resulted in reduced tumor formation in nude mice. Further, to determine whether suppressing the activity of cathepsin B by cystatin A would achieve the same result, we used cystatin A overexpression using sense-transfected cells and observed that these cells did not form tumors in nude mice upon intracerebral implantation [98]. Not only did suppression of cathepsin B retard tumor formation, other aspects of tumor malignancy, such as angiogenesis, were also reduced [99]. In most cases though, targeting cathepsin B alone did not significantly reduce tumor burden. Therefore, we asked whether using a combination approach would be the next logical approach. We simultaneously downregulated the expression of cathepsin B with one other molecule known to be associated with tumor invasion and migration, such as UPAR, and observed that the simultaneous downregulation of uPAR and Cathepsin B using the antisense approach inhibited tumor growth, invasion, and angiogenesis [100]. It is known that for antisense to function, an equal molar ratio of the antisense molecule to the target 
mRNA is required. However in the case of RNAi, such a ratio is not required as the siRNAassociated RISC is recycled and almost has a catalytic function [101-103]. Therefore, we attempted to use the RNAi approach to target cathepsin B. We used the RNAi approach to simultaneously downregulate MMP-9 and cathepsin B and in the direct intratumoral injections of plasmids expressing hpRNA targeting MMP-9 and cathepsin B. We observed that this approach significantly inhibited established glioma tumor growth and invasion in intracranial tumors in vivo [104]. Using a similar approach, we simultaneously downregulated UPAR and cathepsin B using the RNAi approach where intratumoral injections of plasmids expressing hpRNA targeting uPAR and cathepsin $B$ resulted in the regression of pre-established intracranial tumors. Further, RNAi for uPAR and cathepsin B inhibited cell proliferation, reduced the levels of pERK and pFAK [105], and altered the cellular cytoskeleton, which retarded motility and migration of tumor cells [106] and initiated a partial extrinsic apoptotic cascade accompanied by the nuclear translocation of AIF [107]. In addition to our studies in gliomas, we also observed that RNAi-mediated downregulation of cathepsin B and MMP-9 led to decreased tumor growth, invasion and angiogenesis in malignant meningioma cell line [108]. These studies show the effectiveness of simultaneously downregulating two tumor-associated molecules. Simultaneous downregulation of two molecules-one of which is cathepsin B-has shown to be effective at retarding tumor burden and tumor-associated phenomena, such as angiogenesis. Similar results were also observed in prostate cancer cells [109] where targeting MMP-9, uPAR, and cathepsin B inhibited invasion, migration and activated apoptosis. Clearly, the simultaneous downregulation of cathepsin B along with one other tumor-associated molecule appears to have a synergistic effect when compared to downregulating cathepsin B alone.

Understanding the mechanisms associated with tumor suppression mediated by cathepsin B downregulation will enable the development of treatment strategies aimed at treating cancers where cathepsin B overexpression is observed. It was observed that downregulation of UPAR and cathepsin B initiates a caspase-dependent mitochondrial apoptosis in U251 cells and caspase-independent mitochondrial apoptosis in 5310 cells, thereby indicating that the mechanism of apoptotic induction via suppression of uPAR and cathepsin B can vary from cell type to cell type $[110,111]$. The addition of another component to this combinational approach is the use of radiation. It has been observed that collateral radiation damage [112] affects normal cells differently than tumor cells. The next logical strategy would be to sensitize these cancer cells to radiation without severely affecting normal cells. This was partially achieved by suppressing cathepsin B where the simultaneous downregulation of uPAR and cathepsin B (pUC) in combination with radiation was shown to have a greater potential application for the treatment of human meningioma [113]. It was also shown that the simultaneous downregulation of UPAR and cathepsin B inhibits radiation-induced PKCintegrated integrin signaling to the cytoskeleton of glioma-initiating cells [114]. All of these studies show that the suppression of cathepsin B has high therapeutic significance. A recent screening of ongoing clinical trials has revealed that, at present, no study is in progress that directly targets cathepsin B as a therapeutic target. Expression of cathepsin B is only being used as a marker to study the effect of various chemotherapy and bio-therapy products being investigated. From all the previous research reports, we see that targeting cathepsin B alone would not be sufficient to eliminate tumors. A multifaceted approach either targeting multiple molecules, including cathepsin B, or using a combination of chemotherapy or radiation along with targeting cathepsin $\mathrm{B}$, seems to be a more appropriate approach.

\section{Conclusion}

From the review of literature, it is evident that cathepsin B is a versatile molecule with numerous biological roles. The role of cathepsin $\mathrm{B}$ in cancer progression and the metastatic 
process is clear. Therefore, targeting cathepsin B would have significant clinical relevance in the treatment of various cancers.

\section{Expert Opinion}

Cathepsin B has been linked to tumor progression and metastasis. The broad influence of cathepsin B on various aspects of tumor survival and growth makes it an attractive target for cancer therapy. It is clear that targeting cathepsin B has significant therapeutic benefit. Moreover, it is evident that targeting cathepsin B alone does not completely diminish or suppress tumor progression. As researchers have shown, it is possible that cathepsin B can influence signaling events both at the cytoplasmic and nuclear levels and may also be involved in mitochondrial signaling, thereby placing it at a higher level in the signaling cascade than previously thought. Whether the expression of cathepsin functions as a signal initiator or is the product of a signaling event associated with tumor progression still remains unclear. As seen in immune cells, such as macrophages, which have high levels of lysosomal cathepsin B but no pericellular localization of cathepsin B as seen in tumor cells, it appears that the cellular location of cathepsin B plays an important part in its functioning. It is not clear whether global suppression in normal cells of cathepsin B activity or expression would produce unintended effects or cause the activation of or suppression of unwanted pathways and this still remains to be studied. A localized approach to target the expression of cathepsin B would be more relevant.

Moreover, suppression of cathepsin B at the cellular level in vitro cannot model the effects in vivo. More robust and clinically relevant studies need to be performed to highlight the importance of targeting cathepsin B. However, targeting cathepsin B alone does not abolish tumor growth, which is probably because cathepsin B appears to have diverse functions and influence numerous pathways. Therefore, a more prudent approach would be to target multiple molecules to achieve a clinically relevant outcome.

\section{Acknowledgments}

Support for this work from the NCI grant (Cathepsin B grant) to JSR is acknowledged. We thank Sushma Jasti, Debbie McCollum and Diana M. Meister for manuscript review and preparation.

\section{Reference List}

1. Lichtenstein N, Fruton JS. A Studies on Beef Spleen Cathepsin A. Proc Natl Acad Sci U S A. 1960; 46:787-91. [PubMed: 16590672]

2. Greembaum LM, Fruton JS. Purification and properties of beef spleen cathepsin B. J Biol Chem. 1957; 226:173-80. [PubMed: 13428750]

3. Tallan HH, Jones ME, Fruton JS. On the proteolytic enzymes of animal tissues. X. Beef spleen cathepsin C. J Biol Chem. 1952; 194:793-805. [PubMed: 14927673]

4. Press EM, Porter RR, Cebra J. The isolation and properties of a proteolytic enzyme, cathepsin D, from bovine spleen. Biochem J. 1960; 74:501-14. [PubMed: 14434765]

5. Lapresle C, Webb T. The purification and properties of a proteolytic enzyme, rabbit cathepsin E, and further studies on rabbit cathepsin D. Biochem J. 1962; 84:455-62. [PubMed: 14462361]

6. Dingle JT, Blow AM, Barrett AJ, Martin PE. Proteoglycan-degrading enzymes. A radiochemical assay method and the detection of a new enzyme cathepsin. F Biochem J. 1977; 167:775-85.

7. Malemud CJ, Janoff A. Human polymorphonuclear leukocyte elastase and cathepsin G mediate the degradation of lapine articular cartilage proteoglycan. Ann N Y Acad Sci. 1975; 256:254-62. [PubMed: 126033]

8. Kirschke H. Cathepsin H: an endoaminopeptidase. Acta Biol Med Ger. 1977; 36:1547-8. [PubMed: 616702] 
9. Liao JC, Lenney JF. Cathepsins J and K: high molecular weight cysteine proteinases from human tissues. Biochem Biophys Res Commun. 1984; 124:909-16. [PubMed: 6439198]

10. Kirschke H, Langner J, Wiederanders B, Cathepsin L, et al. A new proteinase from rat-liver lysosomes. Eur J Biochem. 1977; 74:293-301. [PubMed: 15835]

11. Velasco G, Ferrando AA, Puente XS, et al. Human cathepsin O Molecular cloning from a breast carcinoma, production of the active enzyme in Escherichia coli, and expression analysis in human tissues. J Biol Chem. 1994; 269:27136-42. [PubMed: 7929457]

12. Kirschke H, Schmidt I, Wiederanders B, Cathepsin S. The cysteine proteinase from bovine lymphoid tissue is distinct from cathepsin L (EC 3.4.22. 15). Biochem J. 1986; 240:455-9. [PubMed: 3814093]

13. Hargrove JL, Gohda E, Pitot HC, Granner DK. Cathepsin T (convertase) generates the multiple forms of tyrosine aminotransferase by limited proteolysis. Biochemistry. 1982; 21:283-9. [PubMed: 6122464]

14. Adachi W, Kawamoto S, Ohno I, et al. Isolation and characterization of human cathepsin V: a major proteinase in corneal epithelium. Invest Ophthalmol Vis Sci. 1998; 39:1789-96. [PubMed: 9727401]

15. Linnevers C, Smeekens SP, Bromme D. Human cathepsin W, a putative cysteine protease predominantly expressed in CD8+ T-lymphocytes. FEBS Lett. 1997; 405:253-9. [PubMed: 9108299]

16. Sakamoto E, Sakao Y, Taniguchi Y, Yamafuji K. Cathepsin Y (a novel thiol enzyme) produces kinin potentiating peptide from the component protein of rat plasma. Immunopharmacology. 1999; 45:207-14. [PubMed: 10615013]

17. Santamaria I, Velasco G, Pendas AM, et al. Cathepsin Z, a novel human cysteine proteinase with a short propeptide domain and a unique chromosomal location. J Biol Chem. 1998; 273:16816-23. [PubMed: 9642240]

18. Rempel SA, Rosenblum ML, Mikkelsen T, et al. Cathepsin B expression and localization in glioma progression and invasion. Cancer Res. 1994; 54:6027-31. [PubMed: 7954439]

19. Krepela E, Kasafirek E, Novak K, Viklicky J. Increased cathepsin B activity in human lung tumors. Neoplasma. 1990; 37:61-70. [PubMed: 2320181]

20. Sinha AA, Morgan JL, Buus RJ, et al. Cathepsin B expression is similar in African-American and Caucasian prostate cancer patients. Anticancer Res. 2007; 27:3135-41. [PubMed: 17970054]

21. Sinha AA, Gleason DF, Deleon OF, et al. Localization of a biotinylated cathepsin B oligonucleotide probe in human prostate including invasive cells and invasive edges by in situ hybridization. Anat Rec. 1993; 235:233-40. [PubMed: 7678371]

22. Krepela E, Vicar J, Cernoch M. Cathepsin B in human breast tumor tissue and cancer cells. Neoplasma. 1989; 36:41-52. [PubMed: 2704424]

23. Murnane MJ, Sheahan K, Ozdemirli M, Shuja S. Stage-specific increases in cathepsin B messenger RNA content in human colorectal carcinoma. Cancer Res. 1991; 51:1137-42. [PubMed: 1997157]

24. Frosch BA, Berquin I, Emmert-Buck MR, et al. Molecular regulation, membrane association and secretion of tumor cathepsin B. APMIS. 1999; 107:28-37. [PubMed: 10190277]

25. Yano M, Hirai K, Naito Z, et al. Expression of cathepsin B and cystatin C in human breast cancer. Surg Today. 2001; 31:385-9. [PubMed: 11381499]

26. Fong D, Chan MM, Hsieh WT, et al. Confirmation of the human cathepsin B gene (CTSB) assignment to chromosome 8. Hum Genet. 1992; 89:10-2. [PubMed: 1577456]

27. Hughes SJ, Glover TW, Zhu XX, et al. A novel amplicon at 8p22-23 results in overexpression of cathepsin B in esophageal adenocarcinoma. Proc Natl Acad Sci USA. 1998; 95:12410-5. [PubMed: 9770500]

28. Lin L, Aggarwal S, Glover TW, et al. A minimal critical region of the 8p22-23 amplicon in esophageal adenocarcinomas defined using sequence tagged site-amplification mapping and quantitative polymerase chain reaction includes the GATA-4 gene. Cancer Res. 2000; 60:1341-7. [PubMed: 10728696]

29. Low JS, Tao Q, Ng KM, et al. A novel isoform of the 8p22 tumor suppressor gene DLC1 suppresses tumor growth and is frequently silenced in multiple common tumors. Oncogene. 2011; 30:1923-35. [PubMed: 21217778] 
30. Knowles MA, Aveyard JS, Taylor CF, et al. Mutation analysis of the 8p candidate tumour suppressor genes DBC2 (RHOBTB2) and LZTS1 in bladder cancer. Cancer Lett. 2005; 225:12130. [PubMed: 15922864]

31. Matas N, Thygesen P, Stacey M, et al. Mapping AAC1, AAC2 and AACP, the genes for arylamine $\mathrm{N}$-acetyltransferases, carcinogen metabolising enzymes on human chromosome $8 \mathrm{p} 22$, a region frequently deleted in tumours. Cytogenet Cell Genet. 1997; 77:290-5. [PubMed: 9284941]

32. Matas N, Thygesen P, Stacey M, et al. Mapping AAC1, AAC2 and AACP, the genes for arylamine $\mathrm{N}$-acetyltransferases, carcinogen metabolising enzymes on human chromosome 8p22, a region frequently deleted in tumours. Cytogenet Cell Genet. 1997; 77:290-5. [PubMed: 9284941]

33. Mueller-Steiner S, Zhou Y, Arai H, et al. Antiamyloidogenic and neuroprotective functions of cathepsin B: implications for Alzheimer's disease. Neuron. 2006; 51:703-14. [PubMed: 16982417]

34. Liang Q, Ouyang X, Schneider L, Zhang J. Reduction of mutant huntingtin accumulation and toxicity by lysosomal cathepsins D and B in neurons. Mol Neurodegener. 2011; 6:37. [PubMed: 21631942]

35. Uchiyama Y. Autophagic cell death and its execution by lysosomal cathepsins. Arch Histol Cytol. 2001; 64:233-46. [PubMed: 11575420]

36. Yang CN, Shiao YJ, Shie FS, et al. Mechanism mediating oligomeric Abeta clearance by naive primary microglia. Neurobiol Dis. 2011; 42:221-30. [PubMed: 21220023]

37. Szpaderska AM, Frankfater A. An intracellular form of cathepsin B contributes to invasiveness in cancer. Cancer Res. 2001; 61:3493-500. [PubMed: 11309313]

38. Wu D, Wang H, Li Z, et al. Cathepsin B may be a potential biomarker in cervical cancer. Histol Histopathol. 2012; 27:79-87. [PubMed: 22127599]

39. Beckham TH, Lu P, Cheng JC, et al. Acid ceramidase-mediated production of sphingosine 1phosphate promotes prostate cancer invasion through upregulation of cathepsin B. Int J Cancer. 2012; 131:2034-43. [PubMed: 22322590]

40. Gopinathan A, Denicola GM, Frese KK, et al. Cathepsin B promotes the progression of pancreatic ductal adenocarcinoma in mice. Gut. 2012; 61:877-84. [PubMed: 22157328]

41. Girotti MR, Fernandez M, Lopez JA, et al. SPARC promotes cathepsin B-mediated melanoma invasiveness through a collagen I/alpha2beta1 integrin axis. J Invest Dermatol. 2011; 131:243847. [PubMed: 21850018]

42. Pavlova A, Bjork I. Grafting of features of cystatins C or B into the N-terminal region or second binding loop of cystatin A (stefin A) substantially enhances inhibition of cysteine proteinases. Biochemistry. 2003; 42:11326-33. [PubMed: 14503883]

43. Pol E, Bjork I. Role of the single cysteine residue, Cys 3, of human and bovine cystatin B (stefin B) in the inhibition of cysteine proteinases. Protein Sci. 2001; 10:1729-38. [PubMed: 11514663]

44. Mai J, Finley RL Jr, Waisman DM, Sloane BF. Human procathepsin B interacts with the annexin II tetramer on the surface of tumor cells. J Biol Chem. 2000; 275:12806-12. [PubMed: 10777578]

45. Qian F, Frankfater A, Chan SJ, Steiner DF. The structure of the mouse cathepsin B gene and its putative promoter. DNA Cell Biol. 1991; 10:159-68. [PubMed: 2012677]

46. Konduri S, Lakka SS, Tasiou A, et al. Elevated levels of cathepsin B in human glioblastoma cell lines. Int J Oncol. 2001; 19:519-24. [PubMed: 11494030]

47. Fais S. Cannibalism: a way to feed on metastatic tumors. Cancer Lett. 2007; 258:155-64. [PubMed: 17977647]

48. Somanna A, Mundodi V, Gedamu L. Functional analysis of cathepsin B-like cysteine proteases from Leishmania donovani complex. Evidence for the activation of latent transforming growth factor beta. J Biol Chem. 2002; 277:25305-12. [PubMed: 12000761]

49. Kostoulas G, Lang A, Nagase H, Baici A. Stimulation of angiogenesis through cathepsin B inactivation of the tissue inhibitors of matrix metalloproteinases. FEBS Lett. 1999; 455:286-90. [PubMed: 10437790]

50. Qian F, Chan SJ, Achkar C, et al. Transcriptional regulation of cathepsin B expression in B16 melanomas of varying metastatic potential. Biochem Biophys Res Commun. 1994; 202:429-36. [PubMed: 8037744] 
51. Berquin IM, Sloane BF. Cathepsin B expression in human tumors. Adv Exp Med Biol. 1996; 389:281-94. [PubMed: 8861022]

52. Berquin IM, Yan S, Katiyar K, et al. Differentiating agents regulate cathepsin B gene expression in HL-60 cells. J Leukoc Biol. 1999; 66:609-16. [PubMed: 10534117]

53. Yan S, Berquin IM, Troen BR, Sloane BF. Transcription of human cathepsin B is mediated by Sp1 and Ets family factors in glioma. DNA Cell Biol. 2000; 19:79-91. [PubMed: 10701774]

54. Sitabkhan Y, Frankfater A. Differences in the expression of cathepsin B in B16 melanoma metastatic variants depend on transcription factor Sp1. DNA Cell Biol. 2007; 26:673-82. [PubMed: 17691867]

55. Jane DT, Morvay LC, Koblinski J, et al. Evidence that E-box promoter elements and MyoD transcription factors play a role in the induction of cathepsin B gene expression during human myoblast differentiation. Biol Chem. 2002; 383:1833-44. [PubMed: 12553720]

56. Yan S, Jane DT, Dufresne MJ, Sloane BF. Transcription of cathepsin B in glioma cells: regulation by an E-box adjacent to the transcription initiation site. Biol Chem. 2003; 384:1421-7. [PubMed: 14669984]

57. Yan S, Sloane BF. Isolation of a novel USF2 isoform: repressor of cathepsin B expression. Gene. 2004; 337:199-206. [PubMed: 15276216]

58. Wellner U, Schubert J, Burk UC, et al. The EMT-activator ZEB1 promotes tumorigenicity by repressing stemness-inhibiting microRNAs. Nat Cell Biol. 2009; 11:1487-95. [PubMed: 19935649]

59. McCormick D. Secretion of cathepsin B by human gliomas in vitro. Neuropathol Appl Neurobiol. 1993; 19:146-51. [PubMed: 8316334]

60. Chapman HA Jr, Munger JS, Shi GP. The role of thiol proteases in tissue injury and remodeling. Am J Respir Crit Care Med. 1994; 150:S155-S159. [PubMed: 7952652]

61. Kreutzberg GW. Microglia, the first line of defence in brain pathologies. Arzneimittelforschung. 1995; 45:357-60. [PubMed: 7763326]

62. Katunuma N. Mechanism and regulation of bone resorption by osteoclasts. Curr Top Cell Regul. 1997; 35:179-92. [PubMed: 9192181]

63. Chan SJ, San SB, McCormick MB, Steiner DF. Nucleotide and predicted amino acid sequences of cloned human and mouse preprocathepsin B cDNAs. Proc Natl Acad Sci U S A. 1986; 83:7721-5. [PubMed: 3463996]

64. Mori H, Tomari T, Koshikawa N, et al. CD44 directs membrane-type 1 matrix metalloproteinase to lamellipodia by associating with its hemopexin-like domain. EMBO J. 2002; 21:3949-59. [PubMed: 12145196]

65. Murphy G, Ward R, Gavrilovic J, Atkinson S. Physiological mechanisms for metalloproteinase activation. Matrix Suppl. 1992; 1:224-30. [PubMed: 1480031]

66. Lindkvist B, Fajardo I, Pejler G, Borgstrom A. Cathepsin B activates human trypsinogen 1 but not proelastase 2 or procarboxypeptidase B. Pancreatology. 2006; 6:224-31. [PubMed: 16534247]

67. Whitcomb DC. Inflammation and Cancer V. Chronic pancreatitis and pancreatic cancer. Am J Physiol Gastrointest Liver Physiol. 2004; 287:G315-G319. [PubMed: 15246966]

68. Burster T, Giffon T, Dahl ME, et al. Influenza A virus elevates active cathepsin B in primary murine DC. Int Immunol. 2007; 19:645-55. [PubMed: 17446210]

69. Anand P, Kunnumakkara AB, Sundaram C, et al. Cancer is a preventable disease that requires major lifestyle changes. Pharm Res. 2008; 25:2097-116. [PubMed: 18626751]

70. Garcia-Cattaneo A, Gobert FX, Muller M, et al. Cleavage of Toll-like receptor 3 by cathepsins B and $\mathrm{H}$ is essential for signaling. Proc Natl Acad Sci U S A. 2012; 109:9053-8. [PubMed: 22611194]

71. Takeda K, Akira S. TLR signaling pathways. Semin Immunol. 2004; 16:3-9. [PubMed: 14751757]

72. Sun R, Zhang Y, Lv Q, et al. Toll-like receptor 3 (TLR3) induces apoptosis via death receptors and mitochondria by up-regulating the transactivating p63 isoform alpha (TAP63alpha). J Biol Chem. 2011; 286:15918-28. [PubMed: 21367858] 
73. Weber A, Kirejczyk Z, Besch R, et al. Proapoptotic signalling through Toll-like receptor-3 involves TRIF-dependent activation of caspase- 8 and is under the control of inhibitor of apoptosis proteins in melanoma cells. Cell Death Differ. 2010; 17:942-51. [PubMed: 20019748]

74. Harashima N, Inao T, Imamura R, et al. Roles of the PI3K/Akt pathway and autophagy in TLR3 signaling-induced apoptosis and growth arrest of human prostate cancer cells. Cancer Immunol Immunother. 2012; 61:667-76. [PubMed: 22038398]

75. Chwieralski CE, Welte T, Buhling F. Cathepsin-regulated apoptosis. Apoptosis. 2006; 11:143-9. [PubMed: 16502253]

76. Bohley P, Seglen PO. Proteases and proteolysis in the lysosome. Experientia. 1992; 48:151-7. [PubMed: 1740187]

77. Tannock IF, Rotin D. Acid pH in tumors and its potential for therapeutic exploitation. Cancer Res. 1989; 49:4373-84. [PubMed: 2545340]

78. Izuishi K, Kato K, Ogura T, et al. Remarkable tolerance of tumor cells to nutrient deprivation: possible new biochemical target for cancer therapy. Cancer Res. 2000; 60:6201-7. [PubMed: 11085546]

79. Ha SD, Martins A, Khazaie K, et al. Cathepsin B is involved in the trafficking of TNF-alphacontaining vesicles to the plasma membrane in macrophages. J Immunol. 2008; 181:690-7. [PubMed: 18566436]

80. Frohlich E, Schaumburg-Lever G, Klessen C. Immunelectron microscopic localization of cathepsin B in human exocrine glands. J Cutan Pathol. 1993; 20:54-60. [PubMed: 8468418]

81. Muntener K, Zwicky R, Csucs G, et al. Exon skipping of cathepsin B: mitochondrial targeting of a lysosomal peptidase provokes cell death. J Biol Chem. 2004; 279:41012-7. [PubMed: 15262981]

82. Riccio M, Di GR, Pianetti S, et al. Nuclear localization of cystatin B, the cathepsin inhibitor implicated in myoclonus epilepsy (EPM1). Exp Cell Res. 2001; 262:84-94. [PubMed: 11139332]

83. Bestvater F, Dallner C, Spiess E. The C-terminal subunit of artificially truncated human cathepsin B mediates its nuclear targeting and contributes to cell viability. BMC Cell Biol. 2005; 6:16. [PubMed: 15807897]

84. Tedelind S, Jordans S, Resemann H, et al. Cathepsin B trafficking in thyroid carcinoma cells. Thyroid Res. 2011; 4(Suppl 1):S2. [PubMed: 21835049]

85. Schwartz MK. Tissue cathepsins as tumor markers. Clin Chim Acta. 1995; 237:67-78. [PubMed: 7664480]

86. Mai J, Waisman DM, Sloane BF. Cell surface complex of cathepsin B/annexin II tetramer in malignant progression. Biochimica et Biophysica Acta. 2000; 1477:215-30. [PubMed: 10708859]

87. Mason SD, Joyce JA. Proteolytic networks in cancer. Trends Cell Biol. 2011; 21:228-37. [PubMed: 21232958]

88. Otto HH, Schirmeister T. Cysteine Proteases and Their Inhibitors. Chem Rev. 1997; 97:133-72. [PubMed: 11848867]

89. Shree T, Olson OC, Elie BT, et al. Macrophages and cathepsin proteases blunt chemotherapeutic response in breast cancer. Genes Dev. 2011; 25:2465-79. [PubMed: 22156207]

90. Muehlenweg B, Assfalg-Machleidt I, Parrado SG, et al. A novel type of bifunctional inhibitor directed against proteolytic activity and receptor/ligand interaction. Cystatin with a urokinase receptor binding site. J Biol Chem. 2000; 275:33562-6. [PubMed: 10913110]

91. Sever N, Filipic M, Brzin J, Lah TT. Effect of cysteine proteinase inhibitors on murine B16 melanoma cell invasion in vitro. Biol Chem. 2002; 383:839-42. [PubMed: 12108549]

92. Puissant A, Colosetti P, Robert G, et al. Cathepsin B release after imatinib-mediated lysosomal membrane permeabilization triggers BCR-ABL cleavage and elimination of chronic myelogenous leukemia cells. Leukemia. 2010; 24:115-24. [PubMed: 19924144]

93. Parker BS, Ciocca DR, Bidwell BN, et al. Primary tumour expression of the cysteine cathepsin inhibitor Stefin A inhibits distant metastasis in breast cancer. J Pathol. 2008; 214:337-46. [PubMed: 17985332]

94. Estrada S, Nycander M, Hill NJ, et al. The role of Gly-4 of human cystatin A (stefin A) in the binding of target proteinases. Characterization by kinetic and equilibrium methods of the interactions of cystatin A Gly-4 mutants with papain, cathepsin B, and cathepsin L. Biochemistry. 1998; 37:7551-60. [PubMed: 9585570] 
95. Li W, Ding F, Zhang L, et al. Overexpression of stefin A in human esophageal squamous cell carcinoma cells inhibits tumor cell growth, angiogenesis, invasion, and metastasis. Clin Cancer Res. 2005; 11:8753-62. [PubMed: 16361563]

96. Mason SD, Joyce JA. Proteolytic networks in cancer. Trends Cell Biol. 2011; 21:228-37. [PubMed: 21232958]

97. Mohanam S, Jasti SL, Kondraganti SR, et al. Down-regulation of cathepsin B expression impairs the invasive and tumorigenic potential of human glioblastoma cells. Oncogene. 2001; 20:3665-73. [PubMed: 11439329]

98. Konduri SD, Yanamandra N, Siddique K, et al. Modulation of cystatin C expression impairs the invasive and tumorigenic potential of human glioblastoma cells. Oncogene. 2002; 21:8705-12. [PubMed: 12483523]

99. Yanamandra N, Gumidyala KV, Waldron KG, et al. Blockade of cathepsin B expression in human glioblastoma cells is associated with suppression of angiogenesis. Oncogene. 2004; 23:2224-30. [PubMed: 14730346]

100. Gondi CS, Lakka SS, Yanamandra N, et al. Adenovirus-mediated expression of antisense urokinase plasminogen activator receptor and antisense cathepsin B inhibits tumor growth, invasion, and angiogenesis in gliomas. Cancer Res. 2004; 64:4069-77. [PubMed: 15205313]

101. Zamore PD, Tuschl T, Sharp PA, Bartel DP. RNAi: double-stranded RNA directs the ATPdependent cleavage of mRNA at 21 to 23 nucleotide intervals. Cell. 2000; 101:25-33. [PubMed: 10778853]

102. Rayburn ER, Zhang R. Antisense, RNAi, and gene silencing strategies for therapy: mission possible or impossible? Drug Discov Today. 2008; 13:513-21. [PubMed: 18549978]

103. Gondi CS, Rao JS. Therapeutic potential of siRNA-mediated targeting of urokinase plasminogen activator, its receptor, and matrix metalloproteinases. Methods Mol Biol. 2009; 487:267-81. [PubMed: 19301652]

104. Lakka SS, Gondi CS, Yanamandra N, et al. Inhibition of cathepsin B and MMP-9 gene expression in glioblastoma cell line via RNA interference reduces tumor cell invasion, tumor growth and angiogenesis. Oncogene. 2004; 23:4681-9. [PubMed: 15122332]

105. Gondi CS, Lakka SS, Dinh DH, et al. RNAi-mediated inhibition of cathepsin B and uPAR leads to decreased cell invasion, angiogenesis and tumor growth in gliomas. Oncogene. 2004; 23:8486-96. [PubMed: 15378018]

106. Gondi CS, Kandhukuri N, Kondraganti S, et al. Down-regulation of uPAR and cathepsin B retards cofilin dephosphorylation. Int J Oncol. 2006; 28:633-9. [PubMed: 16465367]

107. Gondi CS, Kandhukuri N, Kondraganti S, et al. RNA interference-mediated simultaneous downregulation of urokinase-type plasminogen activator receptor and cathepsin B induces caspase-8mediated apoptosis in SNB19 human glioma cells. Mol Cancer Ther. 2006; 5:3197-208. [PubMed: 17172424]

108. Tummalapalli P, Spomar D, Gondi CS, et al. RNAi-mediated abrogation of cathepsin B and MMP-9 gene expression in a malignant meningioma cell line leads to decreased tumor growth, invasion and angiogenesis. Int J Oncol. 2007; 31:1039-50. [PubMed: 17912429]

109. Nalla AK, Gorantla B, Gondi CS, et al. Targeting MMP-9, uPAR, and cathepsin B inhibits invasion, migration and activates apoptosis in prostate cancer cells. Cancer Gene Ther. 2010; 17:599-613. [PubMed: 20448670]

110. Malla R, Gopinath S, Alapati K, et al. Downregulation of uPAR and cathepsin B induces apoptosis via regulation of Bcl-2 and Bax and inhibition of the PI3K/Akt pathway in gliomas. PLoS One. 2010; 5:e13731. [PubMed: 21060833]

111. Gopinath S, Malla RR, Gondi CS, et al. Co-depletion of cathepsin B and uPAR induces G0/G1 arrest in glioma via FOXO3a mediated p27 upregulation. PLoS One. 2010; 5:e11668. [PubMed: 20661471]

112. McBride WH, Chiang CS, Olson JL, et al. A sense of danger from radiation. Radiat Res. 2004; 162:1-19. [PubMed: 15222781]

113. Gupta R, Rao GV, Nalla AK, et al. Oncogenic role of p53 is suppressed by si-RNA bicistronic construct of uPA, uPAR and cathepsin-B in meningiomas both in vitro and in vivo. Int J Oncol. 2011; 38:973-83. [PubMed: 21290090] 
114. Alapati K, Gopinath S, Malla RR, et al. uPAR and cathepsin B knockdown inhibits radiationinduced PKC integrated integrin signaling to the cytoskeleton of glioma-initiating cells. Int $\mathbf{J}$ Oncol. 2012; 41:599-610. [PubMed: 22641287] 


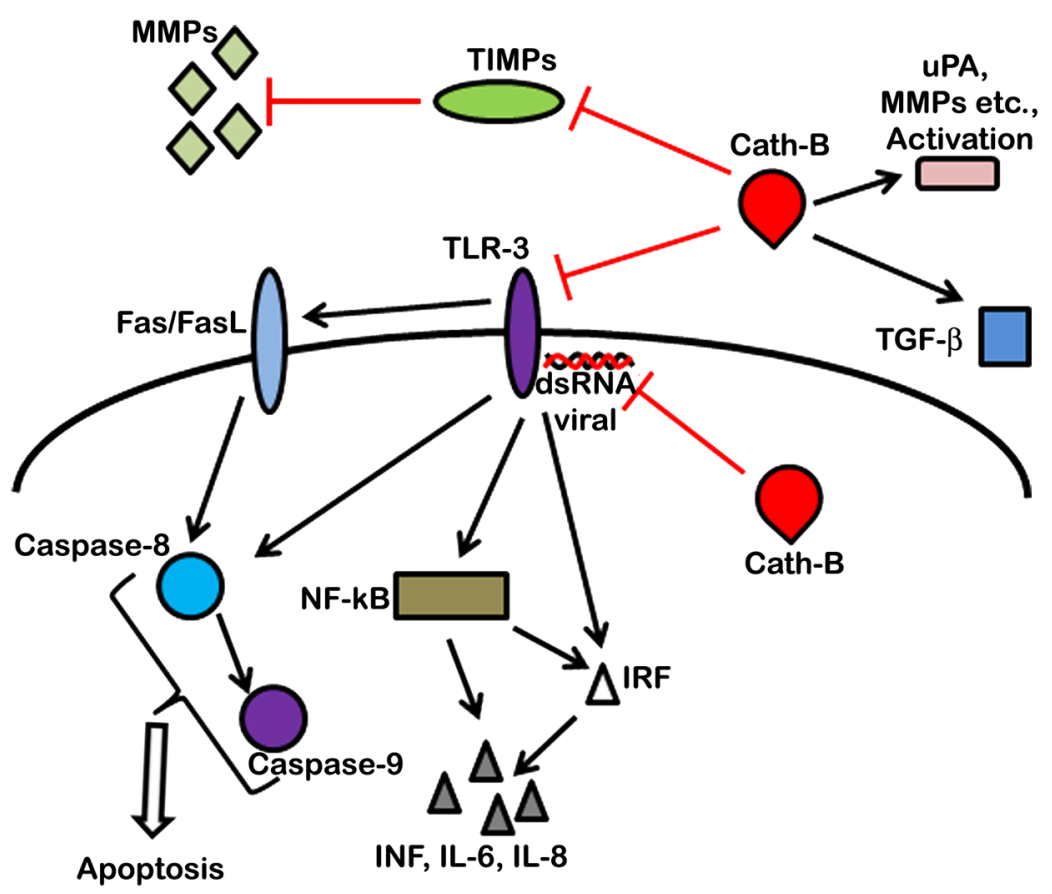

Figure 1.

Schematic representation showing the signaling and protease cascade events mediated by cathepsin B on tumor cells. 


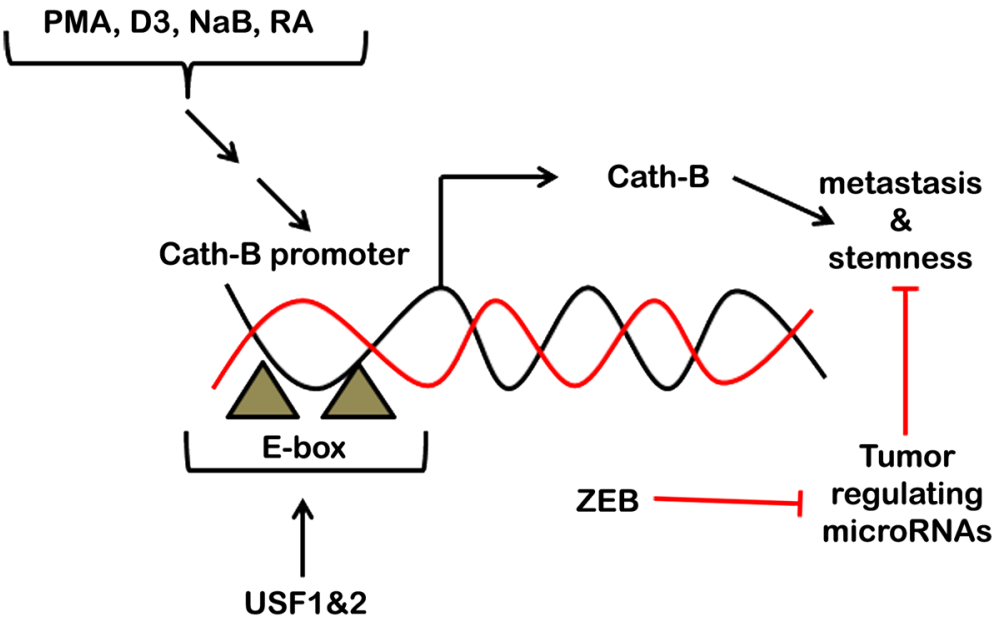

Figure 2. 


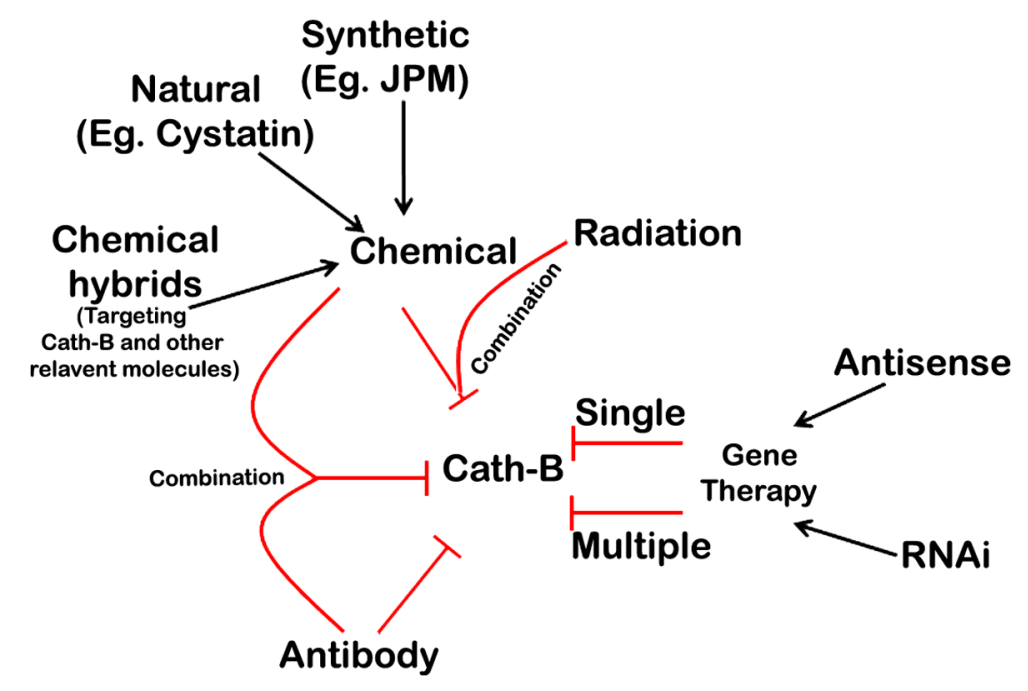

Figure 3 . 